\title{
Influence of Iron on the Size and Distribution of Metallic Lanthanum Particles in Free-machining Titanium Alloys Ti 6Al 7Nb XFe 0.9La
}

\author{
Florian Brunke $^{1, a}$, Eike Meyer-Kornblum ${ }^{1, b}$ and Carsten Siemers ${ }^{1, c}$ \\ Technische Universität Braunschweig, Institute for Materials, Langer Kamp 8, \\ 38106 Braunschweig, Germany
}

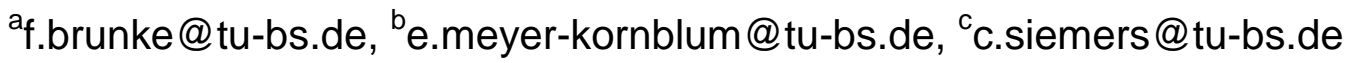

Keywords: Titanium alloys, Ti 6Al 7Nb, rare-earth metals, Lanthanum, free-machining alloy

\begin{abstract}
The addition of the rare earth metal Lanthanum to $(\alpha+\beta)$-Titanium alloys like Ti 6Al 4V or $\mathrm{Ti} 6 \mathrm{Al} 7 \mathrm{Nb}$ improves their machinability as short chips form during machining. In related alloys, metallic Lanthanum is distributed as micrometer-size particles which are mainly located at the grain boundaries. In case Iron is present in Lanthanum containing $(\alpha+\beta)$-Titanium alloys, a more homogeneous particle distribution is observed leading to improved ductility at room temperature and elevated temperature compared to Iron-free alloys. In the present study, the influence of Iron on the Lanthanum particle size and distribution was investigated in the system $\mathrm{Ti} 6 \mathrm{Al} 7 \mathrm{Nb} X \mathrm{Fe} 0.9 \mathrm{La}$. First, the solidification behavior was simulated. Afterwards, alloys with different amounts of Iron $(0.25 \%, 0.5 \%$ and $1.0 \%)$ were produced. The microstructure of these alloys as well as their deformability and mechanical properties at room temperature were analyzed which were improved compared to the Iron-free $\mathrm{Ti} 6 \mathrm{Al} 7 \mathrm{Nb} 0.9 \mathrm{La}$ and $\mathrm{Ti} 6 \mathrm{Al} 4 \mathrm{~V} 0.9 \mathrm{La}$ alloys.
\end{abstract}

\section{Introduction}

Due to their outstanding properties like high specific strength, excellent corrosion resistance and biocompatibility Titanium alloys are widely used in the fields of aerospace and medical engineering $[1,2]$. On the other hand, the application of titanium alloys in many industrial areas is limited due to high material costs of Titanium components. These can be laid back to the raw material price of Titanium as well as to the costs related to component manufacturing [3].

Complex geometries have to be realized by different machining processes. As casting and welding of Titanium products are difficult, the material removal can be up to $50 \%$ (in special aerospace application even 90\%) of the semi-finished product [4]. Titanium machining is a timeconsuming process as only low cutting speeds can be applied. In addition, Titanium alloys are known to form long chips during machining operations, especially during turning and drilling. These long chips can wrap around the workpiece, the turning chisel or get stuck between the drill and the hole leading to poor surface quality, rapid tool wear and tool failure. Therefore, the cutting process cannot be automated as the machining operation has to be interrupted as often as it is necessary to remove the long chips by an operator [5].

The chip formation process of the Ti $6 \mathrm{Al} 4 \mathrm{~V}$ alloy has been studied in detail in experiments and simulations [6]. Based on these results, modified alloys have been developed by the addition of the rare earth metal element Lanthanum. The solubility of Lanthanum in Titanium is very poor. Consequently, metallic Lanthanum particles form which are mainly located on the grain boundaries. This can be explained by the melting point of Lanthanum (approx. $920^{\circ} \mathrm{C}$ ) which is much lower than that of Titanium (approx. $1670^{\circ} \mathrm{C}$ ). During crystallization, Titanium solidifies first and the remaining melt is enriched in Lanthanum. Finally, equiaxed Lanthanum particles crystallize on the grain boundaries. The size of the particles in $\mathrm{Ti} 6 \mathrm{Al} 4 \mathrm{~V} 0.9 \mathrm{La}$ is less than $10 \mu \mathrm{m}$.

During machining of $\mathrm{Ti} 6 \mathrm{Al} 4 \mathrm{~V}$ and other $(\alpha+\beta)$-Titanium alloys, segmented chips are formed having a saw-tooth-like morphology. The segments are separated by shear bands, a narrow region of severe plastic deformation. During shear band formation, the temperature can easily exceed $1000^{\circ} \mathrm{C}$ [7]. Therefore, if Lanthanum particles are located in a shear band they soften or even melt. This causes a reduced adhesion between the single segments and the chips can separate so that short 
chip formation is observed. The advantages of these free-machining alloys are improved surface quality and reduced manufacturing time and, hence, cost reduction during component manufacturing as cutting operations can be automated. On the other hand, the (relatively soft) particles weaken the grain boundaries and cause a reduced fatigue strength and ductility [8].

To overcome these problems, two complex, Iron containing alloys $\mathrm{Ti} 6 \mathrm{Al} 2 \mathrm{Fe} 1 \mathrm{Mo} 0.9 \mathrm{La} 0.5 \mathrm{Cu}$ (Ti-FM) and $\mathrm{Ti} 6 \mathrm{Al} 2 \mathrm{Fe} 1 \mathrm{Mo} 0.9 \mathrm{La} 0.5 \mathrm{Cu} 0.3 \mathrm{Si}$ (Ti-FMS) were developed. On the one hand, the microstructure of these alloys showed a more homogeneous particle distribution (beneficiary effect); on the other hand the particle size on the grain boundaries strongly increased to more than $20 \mu \mathrm{m}$ so that during hot deformation, most of the samples broke by crack formation initialized at large particles (disadvantageous). Detailed studies identified Iron to be responsible for the change in particle morphology as it increases the solidification interval of Titanium alloys [9].

Therefore, in the present study, the influence of Iron on the particle distribution of Lanthanum containing $\mathrm{Ti} 6 \mathrm{Al} 7 \mathrm{Nb} X \mathrm{Fe}$ 0.9 La alloys has been investigated. Ti $6 \mathrm{Al} 7 \mathrm{Nb}$ alloy has been chosen, as it shows increased ductility compared to $\mathrm{Ti} 6 \mathrm{Al} 4 \mathrm{~V}$ alloy. First, the solidification intervals of different iron contents $(X)$ have been investigated (Scheil-Gulliver) in ThermoCalc ${ }^{\circledR}$ simulations. Afterwards, alloys with different amounts of Iron, namely $0.25 \%, 0.5 \%$ and $1.0 \%$ (all numbers in this article given in wt.- $\%$ ) were produced. In addition an iron-free $\mathrm{Ti} 6 \mathrm{Al} 7 \mathrm{Nb} 0.9 \mathrm{La}$ alloy was produced as a reference material. The microstructure of these alloys as well as their deformability and the mechanical properties were analyzed. The results were compared to the Iron-free Ti $6 \mathrm{Al} 7 \mathrm{Nb}$ 0.9La alloy and, hence, an optimized Iron content has been identified.

\section{Materials and Methods}

Simulation. The influence of Iron on the solidification behavior of titanium alloys was investigated in simulations. To do so, the software ThermoCalc ${ }^{\circledR}$, Version S, was used together with the Titanium database TTTI3. Scheil-Gulliver solidification simulations are limited by two main reasons: (i) Diffusion in solidified materials is neglected so that the solidus temperature is generally underestimated and (ii) Lanthanum cannot be taken into account in the simulations as it is not included in the TTTI3 database. As the solvability of Lanthanum in Titanium is very small (so that discrete particles develop) it is assumed that its influence on the solidification is limited as well.

Even if the absolute numbers coming from the simulations might be doubtful, trends can be simulated correctly.

Alloy Production and Heat Treatments. The alloys for the experimental investigations were produced in a laboratory-size plasma-beam cold-hearth melting furnace (PB-CHM). The furnace is provided with a water-cooled copper crucible of a capacity of approx. $350 \mathrm{~g}$ Titanium. The material can be cast into a water-cooled cylindrical copper mold (diameter: $13.2 \mathrm{~mm}$, height: $85 \mathrm{~mm}$ ). As raw materials, CP Titanium Grade 2, Lanthanum (99.9\%), Iron (99.95\%), a Niobium-Aluminum pre-alloy $(60 \% \mathrm{Nb}, 40 \% \mathrm{Al})$ and Aluminum (99.99\%) were used. These raw materials were molten to a first ingot, turned and remelted twice to ensure sufficient homogeneity before casting. The resulting bars were solution treated, deformed in a rotary swaging process from $13 \mathrm{~mm}$ to $10 \mathrm{~mm}$, degree of deformation $\phi \approx 0.3$, and recrystallization annealed.

Microstructure and Particle Analyses. Cross-sections of all the different material states were prepared by grinding (Silicon carbide discs up to grain size P $2500 \mathrm{SiC}$ ) and polishing with OPS. After polishing the samples were etched with Kroll's reagent $\left(\mathrm{HF}+\mathrm{H}_{2} \mathrm{O}_{2}+\mathrm{H}_{2} \mathrm{O}\right)$. The microstructure of the specimens was analyzed by means of a Zeiss Imager.M2m optical microscope and by a Leo Gemini 1550 scanning electron microscope.

\section{Results and Discussion}

Alloy System Ti 6Al 2Fe 1Mo 0.9La 0.5Cu (0.3Si). Previous research included the analyses of solidification intervals of several Titanium alloys like $\mathrm{Ti} 6 \mathrm{Al} 2 \mathrm{Fe} 1 \mathrm{Mo} 0.9 \mathrm{La} 0.5 \mathrm{Cu}$, $\mathrm{Ti} 6 \mathrm{Al} 2 \mathrm{Fe} 1 \mathrm{Mo} 0.9 \mathrm{La} 0.5 \mathrm{Cu} 0.3 \mathrm{Si}$ and their modifications with fewer components (e.g. same composition without Copper and/or Molybdenum or Ti 6Al only). While elements like Aluminium 
or Molybdenum showed almost no influence on the solidification interval other elements like Iron or Copper broadened the interval to lower temperatures [10].

The microstructure of these alloys consisted of an $(\alpha+\beta)$-Titanium matrix with homogeneous dispersed Lanthanum particles (grain boundaries and grain bodies). Some grain boundary particles were relatively large (up to $26 \mu \mathrm{m}$ at an Iron content of $2 \%$ ) compared to other Lanthanum containing alloys like Ti 6Al 4V 0.9La. During hot deformation, crack formation was initiated at these large particles and $100 \%$ failure of the samples was observed if the Iron content was higher than $1 \%$.

Alloy System Ti 6Al 7Nb XFe 0.9La. ThermoCalc ${ }^{\circledR}$ simulations performed at the alloy system $\mathrm{Ti} 6 \mathrm{Al} 7 \mathrm{Nb} X \mathrm{Fe}$ with Iron contents between $0 \%$ and $1 \%$ showed a broadening of the solidification interval with increasing Iron contents as well: An amount of $1 \%$ Iron resulted in a solidus temperature decrease of about $300 \mathrm{~K}$ compared to the Iron-free alloy (see Fig. 1).

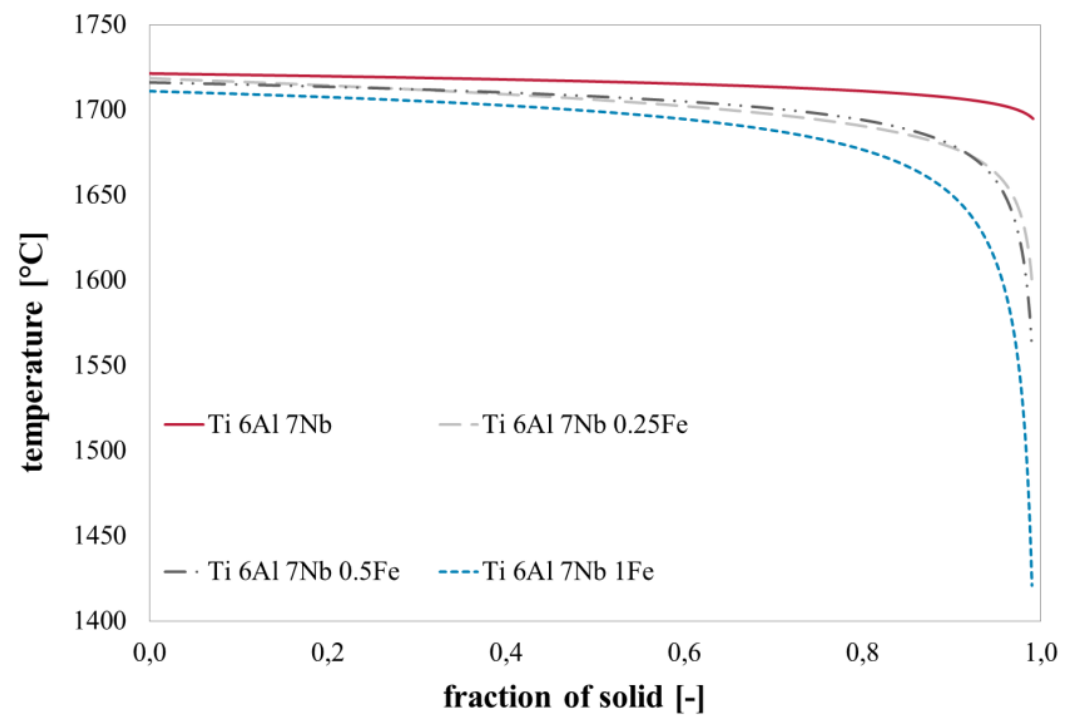

Fig. 1: ThermoCalc ${ }^{\circledR}$ simulations of solidification interval (Scheil-Gulliver). Increased Iron contents broaden the solidification interval.

The microstructure of all experimental alloys consisted of a lamellar $(\alpha+\beta)$-Titanium matrix in the as cast state. The average grain size was about $45 \mu \mathrm{m}$. The grain boundary particles acted as grain refiners and stabilized the grain size up to temperatures of $1100^{\circ} \mathrm{C}$ [11]. In the Iron-free alloy the Lanthanum particles were located on the grain boundaries only (see Fig. 2 left). The average particle size was $1.7 \mu \mathrm{m}$ and the maximum particle size was less than $6 \mu \mathrm{m}$.
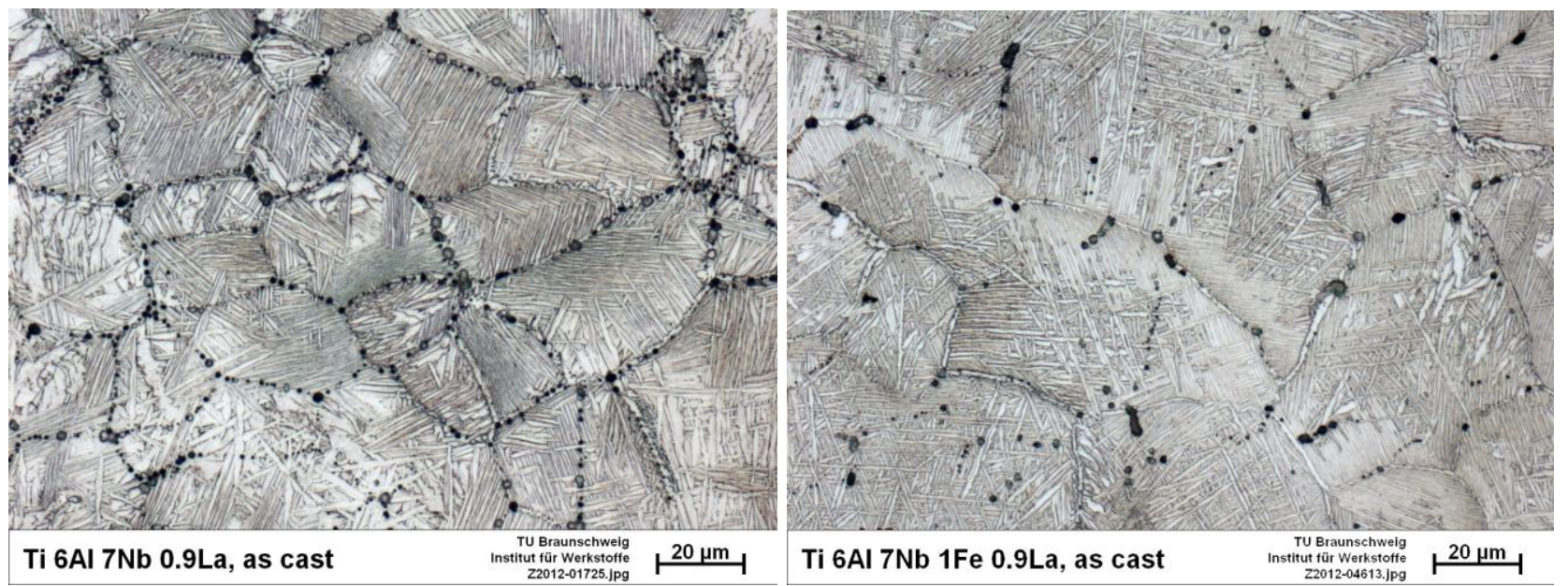

Fig. 2: Microstructure of $\mathrm{Ti} 6 \mathrm{Al} 7 \mathrm{Nb} 0.9 \mathrm{La}$ (left) and $\mathrm{Ti} 6 \mathrm{Al} 7 \mathrm{Nb} 1 \mathrm{Fe} 0.9 \mathrm{La}$ (right) in the as cast state. The La-particles (black dots) are mainly located at the grain boundaries (left). With increased Iron content the particles distribution gets more homogeneous (right). 
With increased Iron content the distribution of the particles got more homogeneous (see Fig. 2, right). The number of grain boundary particles was reduced and the distance between the particles was increased. In addition, particle coarsening was observed. Nevertheless, the maximum particle size was smaller than $10 \mu \mathrm{m}$ (which is similar to the maximum particle size in Ti 6Al 4V 0.9La). Consequently, the number of particles located inside the grains increased with increasing Iron contents as well. In the grains, the particles were located between the lamellae and had an average size of about $1 \mu \mathrm{m}$. Here, the maximum particle size was measured to $3.8 \mu \mathrm{m}$ in the alloy with $1 \% \mathrm{Fe}$ (see Table 1). The homogeneous distribution can be explained by the comparably large solidification interval of the Iron containing alloys so that (i) the grain boundary particles have time to coarsen and (ii) some particles also crystallise in the interdentritic arms which form the grain bodies (matrix) later.

Table 1: Lanthanum particle size and distribution according to Iron contents.

\begin{tabular}{|l|c|c|c|c|}
\hline \multirow{2}{*}{ alloy } & \multicolumn{3}{|c|}{ particle size } \\
\cline { 2 - 5 } & $\begin{array}{c}\text { grain boundary } \\
\text { size }[\mu \mathrm{m}]\end{array}$ & $\begin{array}{c}\text { maximum particle } \\
\text { size }[\mu \mathrm{m}]\end{array}$ & $\begin{array}{c}\text { average particle } \\
\text { size }[\mu \mathrm{m}]\end{array}$ & $\begin{array}{c}\text { maximum particle } \\
\text { size }[\mu \mathrm{m}]\end{array}$ \\
\hline $\mathrm{Ti} 6 \mathrm{Al} 7 \mathrm{Nb} 0.9 \mathrm{La}$ & $1.7 \pm 0.8$ & 5.7 & - & - \\
\hline $\mathrm{Ti} 6 \mathrm{Al} 7 \mathrm{Nb} 0.25 \mathrm{Fe} 0.9 \mathrm{La}$ & $1.4 \pm 0.7$ & 4.9 & $1.0 \pm 0.5$ & 2.6 \\
\hline Ti $6 \mathrm{Al} 7 \mathrm{Nb} 0.5 \mathrm{Fe} 0.9 \mathrm{La}$ & $1.4 \pm 0.7$ & 7.8 & $1.1 \pm 0.6$ & 3.8 \\
\hline Ti $6 \mathrm{Al} 7 \mathrm{Nb} 1 \mathrm{Fe} 0.9 \mathrm{La}$ & $1.8 \pm 1.4$ & 8.6 & $1.0 \pm 0.6$ & 3.8 \\
\hline
\end{tabular}

The deformability of all investigated alloys was good as fewer crack formation and no complete failure was observed during hot deformation. After recrystallization anneal, tensile test specimens have been produced to analyse the mechanical properties. The results are shown in Figure 3. Ti $6 \mathrm{Al} 7 \mathrm{Nb} 0.9 \mathrm{La}$ alloy showed an ultimate tensile strength of approx. $830 \mathrm{~N} / \mathrm{mm}^{2}$ and an elongation at rupture of $8.3 \%$. The $\mathrm{Ti} 6 \mathrm{Al} 7 \mathrm{Nb} 1 \mathrm{Fe} 0.9 \mathrm{La}$ alloy shows with an ultimate strength of $983 \mathrm{~N} / \mathrm{mm}^{2}$ and an elongation at rupture of $11 \%$ (fulfilling the requirements of ASTM B348 for

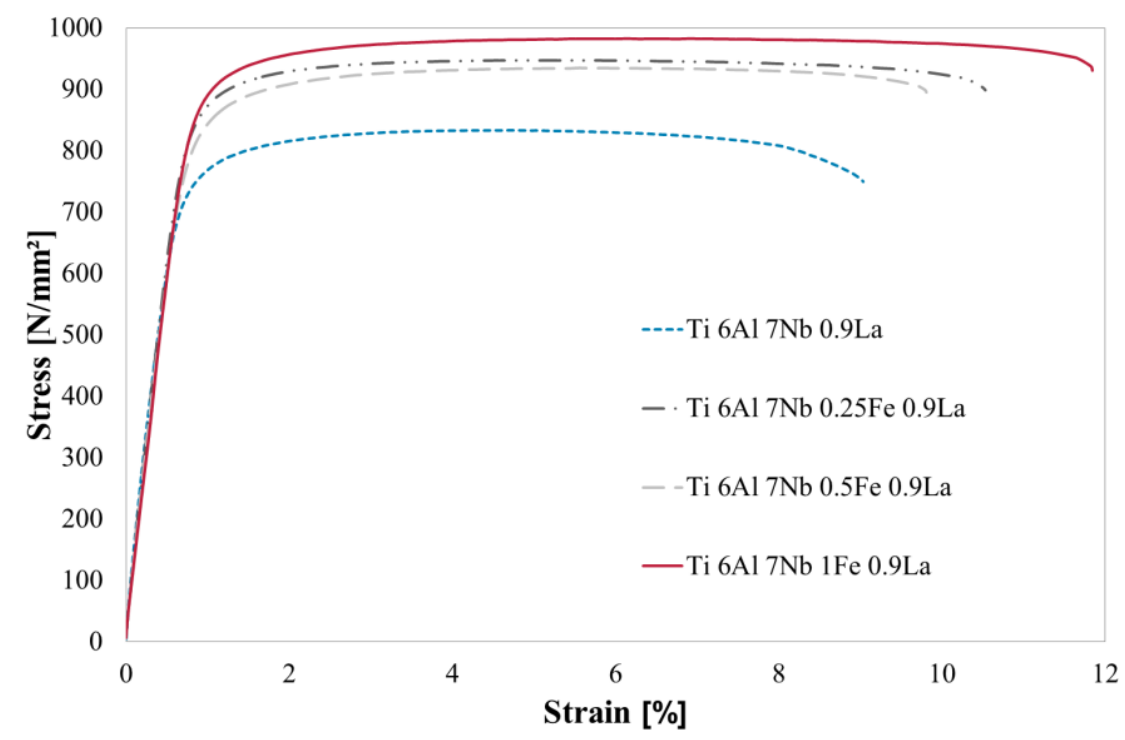

Fig. 3: The diagram shows the tensile test with the best result for each composition. With increased Iron content the ductility and ultimate strength is increased.

$\mathrm{Ti} 6 \mathrm{Al} 4 \mathrm{~V}$ ) the best results. As can be seen from Figure 3, increasing Iron contents increase the strength and the ductility at the same time. This can be explained as follows: (i) Iron is a strong solid solution hardener and, thus, increases the strength of Titanium alloys in general. (ii) Iron causes a more homogeneous particle distribution leading to improved ductility as the grain boundaries are less weakened compared to alloys with particles on the grain boundaries only. (iii) The maximum particle size of $10 \mu \mathrm{m}$ seems to be acceptable as the probability of hot cracking during deformation at elevated temperature is reduced. 


\section{Summary and Outlook}

$(\alpha+\beta)$-alloys like $\mathrm{Ti} 6 \mathrm{Al} 4 \mathrm{~V}$ and $\mathrm{Ti} 6 \mathrm{Al} 7 \mathrm{Nb}$ alloyed with $0.9 \mathrm{La}$ show an improved machinability. At the same time the Lanthanum particles are weakening the grain boundaries resulting in reduced fatigue strength and ductility. By alloying these free-machining alloys with Iron, the particle distribution is getting more homogeneous. The Lanthanum particles are located not only on the grain boundaries but also in the matrix. With increasing Iron contents the particles are dispersed more and more homogeneous but also start to coarsen which is hindering the hot deformation. A maximum Iron content has been identified to $1 \%$ to ensure good deformation properties. In addition, the ductility at room temperature is increased by the more homogeneously dispersed particles. Increasing Iron contents increase the ultimate strength as well and help to reduce the raw material price of the alloy. Therefore, the new alloy system $\mathrm{Ti} 6 \mathrm{Al} 7 \mathrm{Nb} X \mathrm{Fe} 0.9 \mathrm{La}$ might be very interesting for different fields of application in industry.

Future work will now concentrate on $\mathrm{Ti} 6 \mathrm{Al} 7 \mathrm{Nb} 0.9 \mathrm{La}$ alloys containing between $0.5 \%$ and $1 \%$ $\mathrm{Fe}$ as optimal results (particle size and distribution, deformability, strength and ductility) can be expected. Additional mechanical properties as well as the corrosion resistance will be investigated to develop a complete material database which is needed to introduce these free-machining alloys into industrial applications.

\section{Acknowledgements}

Financial support of the Arbeitsgemeinschaft industrieller Forschungsvereinigungen (AiF), project number $16112 \mathrm{~N}$, is gratefully acknowledged.

\section{References}

[1] M. Peters and C. Leyens, Titanium and Titanium Alloys, Wiley-VCH, Germany, 2002.

[2] M. Geetha, A.K. Singh, R. Asokamani, A.K. Gogia, Ti based biomaterials, the ultimate choice for orthopaedic implants - A review, Progress in Materials Science 54 (2009) 397-425.

[3] R. Boyer, G. Welsh and E.W. Collings, Materials Properties Handbook: Titanium Alloys, ASM International, USA, 1994.

[4] G. Lütjering, Titanium, second ed., Springer Verlag, Germany, 2007.

[5] J. Donarchie, Titanium - A Technical Guide, ASM International, USA, 1988.

[6] M. Bäker, Finite Element Investigation of the Flow Stress Dependence of Chip Formation, J. of Mat. Proc. Technol. 167 (2005) 1-13.

[7] C. Siemers, P. Jencus, M. Bäker, J. Rösler, F. Feyerabend, A new free machining Titanium alloy containing Lanthanum, Proc. of the 11th World Conference in Ti, Kyoto, Japan (2007), 709-712.

[8] C. Siemers, F. Brunke, J. Laukart, M.S. Hussain, J. Rösler, K. Saksl and B. Zahra, Rare Earth Metals in Titanium Alloys - A Systematic Study, Proc. of the COM2012, Section Rare Earth Metals 2012, Niagara Falls, Canada, 2012, 281 - 292.

[9] J. Laukart, C. Siemers, J. Rösler, Microstructure Evolution in Ti-Al-Mo-Fe-Mn-Cr-Cu Alloys containing Rare-Earth Metals, Proc. of the 12th World Conference on Ti, Beijing, China (2011), 459-463.

[10] J. Laukart, C. Siemers and J. Rösler, Development of a castable, free-maching titanium alloy, Mat. Sci. For. 690 (2011) 3-6.

[11] C. Siemers, F. Brunke, M. Stache, J. Laukart, B. Zahra, J. Rösler, P. Rockicki, K. Saksl, Advanced Titanium Alloys containing Micrometer-Size Particles, Proc. of the 12th World Conference on Ti, Beijing, China (2011), 883-887. 